\section{UM RELATO DE EXPERIÊNCIA NA FORMAÇÃO INICIAL DE PROFESSORES: UM JOGO PARA O ENSINO DE VACINA A PARTIR DE UMA PERSPECTIVA HISTÓRICA} A report of experience in the initial teacher training: a game for the teaching of Vacine through a
Historical Perspective

Un relato de experiencia en la formación inicial de profesores: un juego para la enseñanza de Vacuna a partir de una perspectiva historica

\section{Resumo}

O presente trabalho tem como objetivo apresentar e discutir uma experiência realizada para o ensino de Vacina, construída no âmbito da disciplina "Metodologia do Ensino de Biologia", ofertada no quarto período do curso de licenciatura em Ciências Biológicas da Universidade Federal de Lavras-MG, buscando entender como o jogo, enquanto recurso pedagógico, auxilia no processo de construção do conhecimento. Além disso, busca discutir a importância da disciplina no processo de formação inicial de professores. A prática fundamentou-se na criação de um jogo para compreender como a vacina funciona no corpo humano e baseou-se na contextualização histórica do conceito. Ao final da prática foi pedido aos alunos para que fizessem uma avaliação apontando os pontos positivos e os pontos a serem melhorados que posteriormente foram analisadas, utilizando a metodologia de pesquisa qualitativa. A partir da análise, foi possível observar a relevância do jogo no processo de apropriação dos conceitos ensinados.

Palavras-Chave: Formação docente; Jogo; Vacina.

\begin{abstract}
The present paper has the purpose of presenting and discussing an experiment carried out for the teaching of Vaccine, constructed within the scope of the Biology Teaching Methodology, offered in the fourth period of the Biological Sciences degree of the Federal University of Lavras-MG, seeking to understand how the game, as a pedagogical resource, assists in the process of building knowledge. Besides that, it seeks to discuss the importance of the discipline in the process of initial teacher training. The practice was based on the creation of a game to understand how the vaccine works in the human body and was based on the contextualization concept. At the end of the practice, students were asked to make an evaluation by the points to be improved that were later analyzed using the qualitative research. From the analysis, it was possible to observe the relevance of the game in the appropriation process of the concepts taught.
\end{abstract}

Keywords: Teacher training; Game; Vaccine.

\section{Resumen}

El presente trabajo tiene el objetivo de presentar y discutir una experiencia realizada para la enseñanza de Vacuna, construida en el ámbito de la disciplina de Metodología de la Enseñanza de Biología, ofrecida en el cuarto período lectivo del curso de licenciatura en Ciencias Biológicas de la Universidad Federal de Lavras- MG, buscando comprender como el juego, mientras recurso pedagógico, auxilia en el proceso de construcción de conocimientos. Además, busca discutir la importancia de la disciplina en el proceso de formación inicial para profesores. La práctica se fundamentó en la creación de un juego para comprender como la vacuna funciona en el cuerpo humano y se basó en el contexto histórico del concepto. Al final de la práctica se pidió a los alumnos para hacer una evaluación apuntando los puntos positivos y los puntos a ser mejorados que posteriormente fueron analizados, utilizando la metodología de investigación cualitativa. A partir del análisis, fue posible observar la relevancia del juego en el proceso de apropiación de los conceptos enseñados.

Palabras clave: Formación docente, juego, vacuna.

\section{AUTORES:}

\section{JULIA AMORIM} MONTEIRO'

ORCID 0000-0001-9639-6270

${ }^{1}$ Universidade Federal de Lavras (UFLA)

AUGUSTO ANTONIO DE PAULA $^{2}$

ORCID 0000-0002-5166-2309

${ }^{2}$ Universidade Federal de Lavras (UFLA)

ANTONIO FERNANDES NASCIMENTO JÚNIOR ${ }^{3}$

ORCID 0000-0003-1326-8113

3 Universidade Federal de Lavras (UFLA)

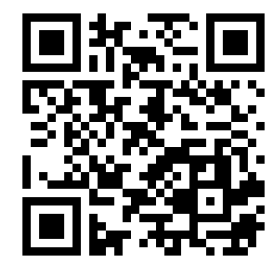

Para citar este artigo:

MONTEIRO, J. A.; PAULA, A. A.; JUNIOR, A. F. N. Um relato de experiência na formação inicial de professores: um jogo para o ensino de vacina a partir de uma perspectiva histórica. Revista Eletrônica Ludus Scientiae, Foz do Iguaçu, v. 03, n. 01, p. 113-123, jan./jul. 2019. 


\section{INTRODUÇÃO}

O ensino de Ciências desempenha um importante papel na formação de sujeitos capazes de reconhecer os fenômenos que acontecem à sua volta, pois permite a compreensão, em sua totalidade, de tais acontecimentos. Sendo assim, Krasilchik (200o, p. 86) destaca que o ensino de Ciências sofreu modificações na "medida em que a Ciência e a Tecnologia foram reconhecidas como essenciais no desenvolvimento econômico, cultural e social", ganhando maior importância nos processos educacionais. Diante disso, cabe à escola o processo de alfabetização científica em que os estudantes se apropriem de todo o conhecimento historicamente construído e acumulado pelo homem, entendendo que o humano é resultado do entrelaçamento do aspecto individual, no sentido biológico, e social, no sentido cultural. Ou seja, ao se apropriar de tudo o que a espécie humana já desenvolveu, o homem se torna humano, e, antes disso, somos animais sem história (MORETTI, 2011).

Nessa perspectiva, Libâneo (2007) afirma que a escola desempenha papel fundamental no processo de desenvolvimento da capacidade intelectual e cognitiva dos alunos, frente a um conjunto de problemas sociais existentes no mundo. Nesse sentido, Oliveira et al. (2013) corroboram dizendo que a escola é a instituição capaz de proporcionar melhores condições de igualdade social em virtude de uma formação de caráter científico, de uma aprendizagem real para aquele que a recebe. Medeiros e Cabral (2006) ressaltam que a sociedade exige uma educação que se comprometa com as transformações sociais.

Por ser social e historicamente construída pela humanidade, a educação exige como cerne de seu progresso uma linguagem múltipla, que englobe toda uma diversidade, entendendo dessa forma, os desafios que envolvem o tecido de formação profissional do professor. "Esta formação constitui um processo que implica em uma reflexão permanente sobre a natureza, os objetivos e as lógicas que presidem a sua concepção de educador enquanto sujeito que transforma e ao mesmo tempo é transformado pelas próprias contingências da profissão" (MEDEIROS; CABRAL, 2006, p. 3). Pensando nessas questões, a disciplina de Metodologia do Ensino de Biologia do curso de Licenciatura em Ciências Biológicas da Universidade Federal de Lavras propôs aos discentes a construção de um currículo a partir do filme "Sonhos Tropicais" dirigido por André Sturm (2001), destacando a importância da atividade na formação docente.

Dessa forma, o presente trabalho apresenta uma experiência realizada no âmbito da disciplina para o ensino de Vacina. O ensino da vacina é importante para a compreensão da realidade, visto que, entender o contexto histórico de sua criação possibilita ao educando a superação de uma possível alienação, já que conseguirá compreender de forma holística as questões econômicas, políticas, sociais, culturais e ambientais que permeiam a relação saúde e doença.

No entanto, Razera et al. (1999) destacam que nos livros didáticos o tema é abordado de maneira em que os conceitos permanecem relativamente uniformes e estáticos, numa abordagem informativa importante, porém fragmentada do contexto, possibilitando induções de prejuízo à apropriação conceitual. Assim, a abordagem conceitual não permite uma ampliação do tema e dos pontos sociais e históricos que o permeiam, restringindo a formação crítica e cidadã dos estudantes.

Ainda, o ensino sobre o tema se torna mais difícil na medida em que o professor faz uso do modelo tradicional de ensino, que segundo Leão (1999) parte do pressuposto que todos os educandos são iguais e, segundo Libâneo (2012), o processo de aprendizagem é reduzido à repetição de conceitos e capacidade de memorização dos alunos. Sendo assim, surge a necessidade de romper com esse modelo de educação que não propicia a emancipação dos estudantes.

Tendo em vista que é necessário romper com o modelo de educação que não propicia a emancipação dos estudantes, o professor passa a ter um papel importante no processo de ensino e aprendizagem, pois no momento em que entende os estudantes como figura central nesse processo, ele deixa de ser um aplicador de conteúdos e assume o papel de norteador, fornecendo então ferramentas para que os estudantes compreendam o mundo em que estão inseridos (TARDIF, LESSARD e LAHAYE, 1991).

Pensando nisso, foi utilizado um jogo para o ensino de vacina, pois assim como destacam Gomes e Friedrich (2001), o jogo pedagógico visa proporcionar a aprendizagem a partir do aspecto 
lúdico, concretizando-se como uma metodologia alternativa de ensino que possibilita melhorar o desempenho de estudantes com dificuldades em se apropriar de determinados conteúdos.

O jogo pedagógico não tem fim em si mesmo, mas serve como fio condutor a um conteúdo didático. Sendo assim, Dessordi et al. (2008) salientam que o jogo possibilita uma aproximação entre os alunos e o conteúdo ensinado. $\mathrm{O}$ jogo se caracteriza como recurso pedagógico na medida em que estimula o interesse do aluno (ZANON et al., 2008). Nessa perspectiva, Jann e Leite (2010, p. 283) evidenciam que o jogo, além de estimular, favorece o desenvolvimento de "diferentes níveis da formação do educando, desde as experiências educativas, físicas, pessoais e sociais". Além disso, atividades na forma de jogos apresentam seu caráter lúdico e motivacional para instigar a atenção dos alunos (KUHNE et al., 2006). Para que isso aconteça é necessário que o professor atue como mediador do processo de ensino.

Diante dessas considerações, o presente trabalho tem como objetivo apresentar e discutir uma metodologia para o ensino de Vacina, construída a partir da disciplina de Metodologia do Ensino de Biologia, buscando entender como o jogo, enquanto recurso pedagógico, auxilia no processo de construção do conhecimento. Além disso, busca discutir a importância da disciplina no processo de formação inicial de professores.

\section{DESENVOLVIMENTO DO TRABALHO}

\section{Proposta da disciplina}

A disciplina de Metodologia do Ensino de Biologia é ofertada no quarto período do curso de Licenciatura em Ciências Biológicas da Universidade Federal de Lavras, UFLA, e tem o objetivo de auxiliar na construção da identidade docente dos licenciandos, contribuindo para que construam metodologias educacionais para o ensino de Biologia no Ensino Médio. Ainda, tem o papel de contribuir com a construção de um olhar crítico nos mesmos, ajudando-os a refletir acerca da realidade em que o processo educativo se insere (PAULA et al., 2015, p.2).

Os discentes assistiram ao filme "Sonhos Tropicais" e foi pedido para que destacassem as questões econômicas, sociais e culturais presentes no longa-metragem para assim discutirem o que poderiam trazer para o currículo que construiriam. Abaixo segue um quadro com a sequência didática construída de forma coletiva e as estratégias pedagógicas de cada aula.

Quadro 1: Sequência didática e estratégias pedagógicas.

\begin{tabular}{|c|c|}
\hline Sequência Didática & Estratégias/Recursos pedagógicos \\
\hline Políticas para a saúde pública & Metodologia problematizadora \\
\hline Relação Saúde e Doença & Dinâmica em grupo \\
\hline Interações Ecológicas & Obra “O abismo do inferno" e notícias \\
\hline Protozoários & Fungos/Placas de Petri \\
\hline Fungos & Reportagem e cultivo de bactérias \\
\hline Resistência Bacteriana & Trabala não foi ministrada não foi desenvolvido \\
\hline Vírus & Jogo \\
\hline Vetores & Imagens e vídeos \\
\hline Relação Parasita-Hospedeiro & \\
\hline Ciclo de Parasitas & \\
\hline
\end{tabular}




\begin{tabular}{|c|c|}
\hline Varíola e Febre Amarela & Dinâmica em grupo \\
\hline Reações imunológicas & Maquete e animação em vídeo \\
\hline Vacinas & Jogo \\
\hline Políticas para a Saúde Pública & Metodologia problematizadora \\
\hline
\end{tabular}

\section{Descrição da aula}

A aula foi iniciada relembrando o que havia sido aprendido nas aulas passadas, visto que houve uma sequência didática lógica para chegar até este tema. A partir de problematizações acerca das aulas passadas, os próprios estudantes chegaram na ideia de "vacina".

Nesse momento, os estudantes foram questionados se sabiam como havia surgido a vacina. Dessa maneira, foi dito o quão importante é compreender os conceitos biológicos em sua totalidade: "como, onde, por quem e para que foi descoberto". Dessa forma, é possível compreender tal conceito em sua totalidade e não de forma descontextualizada e fragmentada, como se não houvesse uma história por trás.

Com isso, novas problematizações foram feitas para construir a história da criação da vacina. A partir disso, se deu a construção do conhecimento acerca de como a vacina funciona no organismo humano. Para isso, a sala foi dividida em quatro grupos e entregue um papel que continha uma parte de uma narrativa. Cada grupo ficou responsável por ler uma parte. Assim, o primeiro grupo leu o início da narrativa, que dizia: "Em uma terra distante há uma civilização dotada de tal inteligência que faz com que seu universo seja invencível, no entanto dois inimigos tentarão provar que nada é tão invencível quanto parece". O segundo grupo leu sua parte da narrativa: "Esse inimigo já vem tentando destruir centenas de outras civilizações, que conseguiram se proteger desse terrível pesadelo, como discutiremos a seguir".

Nesse momento, a partir de perguntas norteadoras, foi possível descobrir quem seriam os possíveis inimigos: os microrganismos. Lembrando sempre que, isso só foi possível devido à sequência didática que as aulas foram postas. Além disso, foi possível também discutir como essas civilizações conseguiram se proteger do inimigo, através de panfletos que traziam datas e locais de vacinação. Com isso, foi perguntado se todos já haviam sido vacinados, se tiveram contato com esse tipo de panfleto e como esses panfletos poderiam ser chamados. Os estudantes prontamente responderam que podiam ser considerados como políticas para saúde pública, chegando em um dos objetivos. Imagens dos panfletos utilizados seguem abaixo:
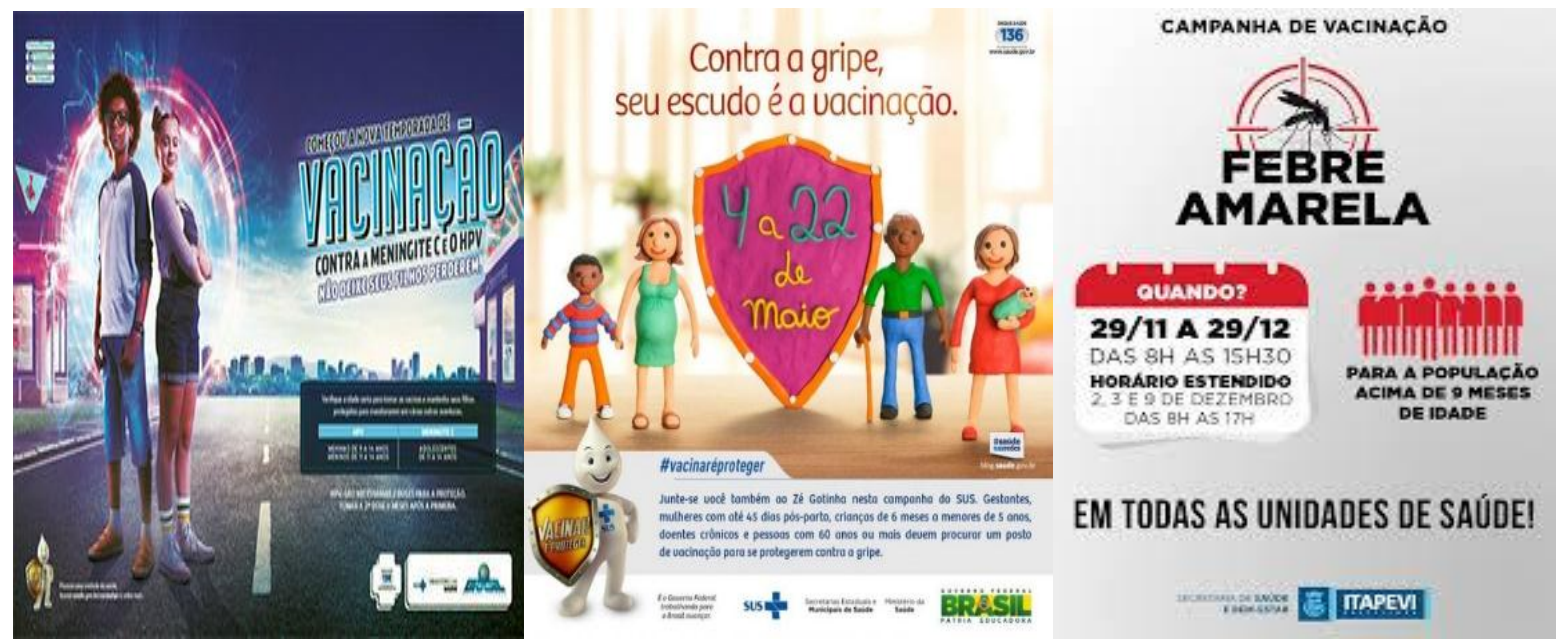

Figura 1, 2 e 3: Panfletos utilizados. 
Dando continuidade ao jogo, o terceiro grupo leu sua parte: "Voltando para a civilização que está prestes a ser invadida. Lá, existe os guardiões que nos ajudarão nessa tarefa. Para isso, baseado em todo o conhecimento que construímos no decorrer das aulas, precisamos pensar em como detê-lo". Posteriormente, o quarto grupo leu: "Para tal, precisamos saber que os guardióes carregam consigo características que podem auxiliar na descoberta de como deter o inimigo. No entanto, cada guardião pode apenas utilizar um de seus atributos". Abaixo seguem as cartas dos guardiões.

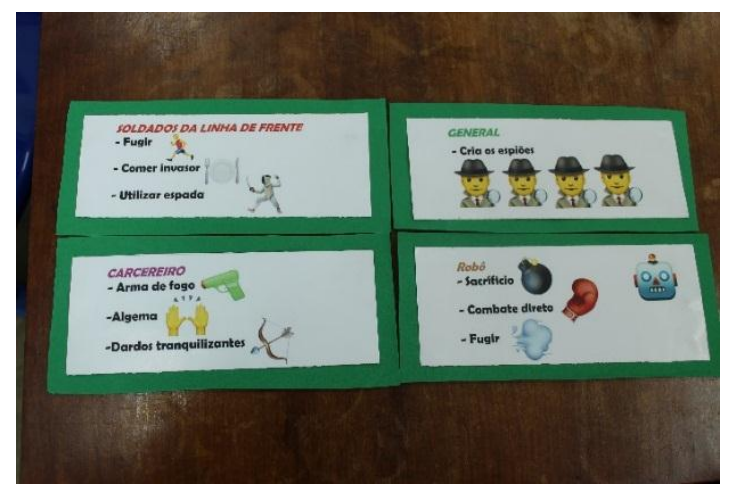

Figura 4: Carta dos guardiões.

Após a apresentação das cartas foi possível, de fato, dar início ao jogo, questionando que, assim que a vacina tem contato com o organismo e baseado em tudo que já foi construído, qual seria o guardião que possivelmente agiria primeiro. Os alunos rapidamente se lembraram do macrófago que foi mencionado na aula anterior e falaram que os soldados da linha de frente seriam os primeiros a ter esse contato e que eles comeriam o invasor. Nesse sentido, foi dito que esse ato de "comer" era chamado de fagocitose, então, foi pedido para que os estudantes anotassem em uma cartolina o nome fictício do personagem, o nome real e a função.

Dando sequência ao jogo, foi pedido para que pensassem e escolhessem o próximo guardião. Os estudantes discutiram entre si e chegaram ao consenso que seria o carcereiro e ele jogaria dardos tranquilizantes para acalmar o invasor. Aqui foi possível discutir o porquê de não poder ser escolhido as outras opções. O invasor poderia se soltar da algema e utilizar a arma de fogo não era interessante, visto que o inimigo poderia morrer de vez sem conseguir retirar algo muito importante dele. Então, foi perguntado se sabiam qual era o nome real da célula que estava sendo representada pelo carcereiro e rapidamente eles disseram que era o linfócito $B$, que produzia os anticorpos que são responsáveis por neutralizar os vírus.

Nesse momento, as células que já tinham aparecido no jogo foram relembradas para breve discussão, para então trazer o terceiro guardião. Os estudantes viram que as opções que eles tinham e mais fazia sentido era o general, pois ele criava os espiões. Esse foi o ponto alto da aula, pois são esses espiões os responsáveis pela memória imunológica, que é capaz de reconhecer um agente infeccioso após o primeiro contato e esse é o princípio da vacina. Aqui os estudantes demoraram para lembrar o nome da célula, no entanto, com as indagações, disseram o nome real (células imunológicas). Agora que os guardiões já haviam imobilizado o invasor, retirado dele informações importantes, sobrou o último guardião, um robô programado para se sacrificar e com isso matar de vez o invasor. A partir desse robô foi discutido a Apoptose, dando fim ao jogo.

Após esse momento foi entregue aos estudantes uma notícia recente sobre a volta de doenças que já haviam sido erradicadas no Brasil. Entre elas, o sarampo, que desde 2013, não se tinha casos, no entanto, nesse ano, já foram constatadas algumas mortes. Após a notícia ser lida, ficaram assustados, pois não sabiam que o vírus do sarampo havia voltado a contaminar as pessoas. Partindo disso, foi possível discutir sobre o papel desempenhado pelo estado nessa situação, visto que ele é responsável por criar políticas para saúde pública. Além disso, foi discutido o fato de que tomar ou não vacina, não deve ser uma escolha individual, pensando sempre que, se alguém não vacinar seu filho, por exemplo, outra criança que tem idade menor e que não pode ser vacinada por não ter idade suficiente, fica 
suscetível a doença. Desse modo, o governo coloca uma meta de que $95 \%$ da população seja vacinada e assim, a probabilidade de algum vírus conseguir achar algum hospedeiro acaba sendo muito menor. Isso é chamado de efeito rebanho. Assim, os estudantes colocaram o papel imprescindível do governo de conscientizar e de oferecer meios para que as pessoas sejam vacinadas e assim zelar pela saúde da população.

Neste instante, pôde ser discutido a respeito da importância de entender como todos esses processos funcionam. Ao entender esses processos, os estudantes ficam instrumentalizados para que possam discutir acerca do assunto e entender a importância da vacina para a saúde pública. Após essa discussão, foi pedido aos alunos, como forma avaliativa, que relacionassem os nomes fictícios dos guardiões com os nomes reais e suas respectivas funções e para que falassem da importância da vacina como políticas para saúde pública, dando fim à aula.

Após o término da aula foi pedido aos licenciandos que escrevessem uma avaliação apontando os pontos positivos e os pontos a serem melhorados na prática desenvolvida. Essas avaliações foram utilizadas para a análise do presente trabalho.

\section{METODOLOGIA}

Para entender como o jogo, enquanto recurso pedagógico, auxilia no processo de construção de conhecimentos e discutir a importância da disciplina Metodologia do Ensino de Biologia no processo de formação inicial de professores foi utilizado a metodologia de pesquisa qualitativa, mais especificamente a análise de conteúdo e a categorização de Minayo (2002).

\section{RESULTADOS E DISCUSSÃO}

A partir da análise das avaliações foram encontradas 4 categorias. Segue abaixo um quadro com as categorias, descrição e frequência.

Quadro 1: Categorias, descrição e frequências.

\begin{tabular}{|l|l|c|}
\hline \multicolumn{1}{|c|}{ Categorias } & \multicolumn{1}{|c|}{ Descrição } & Frequência \\
\hline $\begin{array}{l}\text { Contextualização } \\
\text { histórica }\end{array}$ & $\begin{array}{l}\text { Nesta categoria os estudantes ressaltaram a } \\
\text { importância da contextualização histórica } \\
\text { para a compreensão do conceito de forma } \\
\text { holística. }\end{array}$ & 6 \\
\hline $\begin{array}{l}\text { Jogo como recurso } \\
\text { pedagógico }\end{array}$ & $\begin{array}{l}\text { Agrupam-se as falas que trazem o jogo como } \\
\text { importante recurso para a construção do } \\
\text { conhecimento. }\end{array}$ & 5 \\
\hline Aula dinâmica & $\begin{array}{l}\text { Aqui os estudantes colocaram a dinamicidade } \\
\text { da aula como promissora no processo de } \\
\text { ensino-aprendizagem. }\end{array}$ & 5 \\
\hline $\begin{array}{l}\text { Relação entre as outras } \\
\text { aulas }\end{array}$ & $\begin{array}{l}\text { Aqui foi destacado a relação da aula } \\
\text { apresentada com as aulas anteriores no } \\
\text { processo de compreensão do tema ensinado }\end{array}$ & 4 \\
\hline
\end{tabular}

Na primeira categoria, os estudantes ressaltaram a importância da contextualização histórica no ensino de algum conceito, visto que, esses conceitos surgiram em um tempo e no espaço e conhecer esses fatores torna possível a compreensão do conceito de forma holística. Dessa forma, Matthews (1995) coloca que a contextualização pode humanizar as ciências e aproximá-las dos interesses éticos, culturais e políticos da comunidade, além de poder tornar as aulas mais desafiadoras e reflexivas, permitindo o desenvolvimento do pensamento crítico por parte dos estudantes e educadores. Ao compreender o conceito de forma holística, a partir da contextualização, torna-se possível também identificar a relação entre o que se está estudando com o cotidiano, ressaltando a importância da educação no sentido de compreender a realidade. 
Além disso, trazer o contexto histórico colabora para que haja uma mudança na concepção de que a ciência é retilínea (GURIDI e ARRIASSECQ, 2004). As autoras ainda discutem que esse tipo de abordagem torna possível erradicar visões simplistas sobre a ciência, o que é de suma importância para que os estudantes consigam perceber o método que está por trás do que aprenderam além de passar a ter contato, de fato, com o olhar científico que há nos conceitos que aprendem na escola.

Nesse contexto, Oliveira (2009) relata em sua pesquisa que muitos alunos nem sempre conseguem identificar essa relação e por isso entendem a biologia como uma disciplina de memorização de nomes complexos, classificação e resolução de problemas que não estão ligados com o seu dia a dia. Nesse sentido, os Parâmetros Curriculares Nacionais (BRASIL, 1998), tanto do Ensino Fundamental como do Ensino Médio incorporaram a orientação de que dimensão histórica deve ser introduzida nas séries iniciais e no ensino médio. Nos PCN do Ensino médio, mais especificamente, é destacado que "elementos da história e da filosofia da Biologia tornam possível aos alunos a compreensão de que há uma ampla rede de relações entre a produção científica e o contexto social, econômico e político (p. 32)".

Sendo assim, a contextualização histórica tem um papel fundamental no ensino de biologia, uma vez que a mesma vai contra a ideia a-histórica da ciência (PRETTO, 1985). Dessa forma, a história pode contribuir para a superação da falta de significados que vem inundando as salas de aulas, além de melhorar a formação de professores, auxiliando numa teoria da ciência mais rica e autêntica, ou seja, compreendendo a estrutura da ciência bem como o espaço que ela ocupa (MATTHEWS, 1995).

Na segunda categoria, os licenciandos destacaram a relevância do jogo como recurso pedagógico no processo de construção de conhecimentos. Diante disso, Cunha (2012) enfatiza que é preciso ressaltar que é um desafio à competência de o professor despertar o interesse do aluno no processo de ensino, sendo assim, o docente deve proporcionar situações estimuladoras para a aprendizagem. É nesse contexto que o jogo como recurso pedagógico ganha espaço, pois, segundo Lima (2008), ao ser trabalhado no ambiente educacional, o jogo, possibilita a apropriação dos temas ensinados. Para além disso, Silva e Levandoski (2008) evidenciam que em sala de aula, o jogo possibilita que haja uma discussão entre alunos, em que há uma elaboração coletiva para a solução do problema, com isso, os educandos podem fazer uma análise acerca dos resultados obtidos. Os autores ainda complementam dizendo que essa prática permite ao professor maior compreensão acerca do desenvolvimento do aluno interferindo quando for necessário.

A interação que se dá entre aluno $\mathrm{x}$ aluno e aluno $\mathrm{x}$ professor, promove um ambiente de troca de ideias, de criticidade, de criatividade e de responsabilidade; ambiente esse indispensável ao processo de construção de conhecimentos (SILVA; LEVANDOSKI 2008). Diante disso, o jogo com objetivos pedagógicos pode auxiliar no desenvolvimento escolar dos educandos com dificuldade de aprendizado em determinados conteúdos (GOMES; FRIEDRICH, 2001). Nessa perspectiva, Kishimoto (1996) destaca que o jogo não é o fim, mas um fio condutor a um conteúdo didático específico, em que a partir do lúdico há aquisição de conhecimentos. Com isso, Campos et al. (2003) apontam que apropriação e a aprendizagem significativa de conhecimentos se tornam mais fáceis quando a questão lúdica se alia aos processos de ensino-aprendizagem, pois há um rompimento com o modelo tradicional de ensino tornando a aula mais atrativa.

Nessa perspectiva, Alves e Bianchin (2010), evidenciam que a partir do jogo, os educandos experimentam, inventam, descobrem e aprendem, dessa forma há um desenvolvimento da inteligência e sensibilidade. As autoras ainda afirmam que o jogo também auxilia no "desenvolvimento de habilidades sociais e cognitivas". Ainda, o lúdico auxilia na motivação e desenvolvimento dos educandos (MACAGNAN; NASCIMENTO JUNIOR, 2008). Com isso, é possível inferir que estratégias pedagógicas como essa devem ser mais exploradas no processo de aprendizagem, dessa forma, com a apropriação dos conteúdos, os educandos compreenderão a realidade social na qual estão inseridos e poderão atuar nela com autonomia.

Na categoria "Aulas dinâmicas" os estudantes apontaram a importância de uma aula dinâmica que priorize uma aprendizagem contextualizada onde eles participem ativamente da construção do conhecimento. Nessa perspectiva, segundo Rosa (2012) é preciso reconhecer que antigos métodos de ensino-aprendizagem são falhos atualmente, pois os alunos não aprendem da mesma forma, além de 
não serem os mesmos, possuindo diferentes preocupações e interesses. Sendo assim, é necessárias alternativas que inovem o modo de ensinar e aprender, para tornar a aula um momento inovador que consiga chamar atenção dos estudantes para o aprendizado.

Assim, o professor é o principal responsável por criar fatores que estimulem os estudantes a buscar, pesquisar e a construir os conhecimentos de forma que esse processo seja o mais dinâmico e inovador possível (FRISON; SCHWARTZ, 2002). Com isso, os alunos poderão atuar como protagonistas dentro da sala de aula, posto que o professor vai sair de seu papel como detentor do conhecimento e passará a ser mediador do mesmo. Lima et al. (2011) afirmam que apenas dessa forma os alunos conseguirão compreender os fenômenos e a relação deste, com o homem e a natureza além de poder atuar ativamente na sociedade.

No entanto, para discutir a questão sobre novos métodos de ensino é necessário que se discuta também os processos de formação inicial e continuada de professores, já que assim como evidencia Gatti (2010), os cursos de formação docente do país ainda seguem o modelo consagrado da década de $1930\left(3^{+1}\right)$ em que um curso de bacharel é adicionado disciplinas pedagógicas que não encontram diálogos entre si. Dessa forma, Libâneo (2015) ressalta que esses cursos de formação não cumprem seu papel, pois há uma dicotomia entre os conhecimentos específicos e conhecimentos pedagógicos, ocasionando a formação dos professores especialistas, onde os professores sabem muito de determinado conteúdo, mas não conseguem fazer a articulação desses conhecimentos com a questão pedagógica, dificultando os processos de aprendizagens em sala de aula. Portanto, é necessário e urgente que os cursos de formação docente sejam repensados para que os professores possam cumprir seu papel no auxílio à formação de seus educandos em uma perspectiva crítica e reflexiva.

Na última categoria, foi destacado a relação da aula apresentada com as aulas anteriores no processo de compreensão do tema ensinado, esse apontamento permite perceber a importância que se tem o processo de integração entre os conteúdos, assim, rompe-se com o ensino fragmentado e os educandos passam a compreender o tema de forma holística. Para que isso aconteça, é necessário que haja a elaboração de uma sequência didática, que Zabala $(1998$, p18) define como "um conjunto de atividades ordenadas, estruturadas e articuladas para a realização de certos objetivos educacionais, que têm um princípio e um fim conhecidos tanto pelos professores como pelos alunos", além disso Moreira e Silva (2005) afirmam que o currículo é um artefato social, integrado com relações de poder, produzindo identidades pessoais e sociais, e por isso ele não se restringe somente aos conteúdos que devem ser lecionados.

Nessa concepção, Oliveira (2013) discute os passos básicos para a elaboração de uma sequência didática: perpassando pela escolha do tema a ser trabalhado; os questionamentos para problematização do assunto; planejamento dos conteúdos; objetivos a serem atingidos no processo de ensino-aprendizagem; delimitação da sequência de atividades, levando-se em consideração a formação de grupos, material didático, cronograma, integração entre cada atividade e avaliação dos resultados. É possível perceber que por trás da sequência didática há uma atitude intencional, como se existisse uma relação de correspondência entre o que é projetado, o que se faz de intervenções e o que acontece (UBERTI, 2013). Logo é importante ter em mente a importância de tal sequência e não somente a vontade de criá-la.

Nesse sentido, Nogueira Júnior (2008) aponta que é preciso que haja a articulação das atividades ensinadas, pois só assim, garantirá a construção de um significado em um contexto maior. Certamente, o estudo sem conexões com os diferentes temas ensinados gera dificuldades de apropriação, pois os educandos encontrarão mais dificuldades em estabelecer relações entre o que é aprendido e seu cotidiano, já que terá um olhar reduzido da realidade social na qual estão inseridos. Portanto, é necessário que haja essa integração no processo de ensino para que haja uma aprendizagem significativa.

\section{CONSIDERAÇÕES FINAIS}

A partir da análise do presente trabalho, é possível perceber a relevância da disciplina de Metodologia do Ensino de Biologia no processo de formação inicial de professores, pois permite aos 
discentes a construção de um olhar amplo e crítico acerca do contexto em que o ensino de Ciências e Biologia está inserido. Ao propor a construção de metodologias alternativas de ensino, a disciplina possibilita que os licenciandos mobilizem seus conhecimentos específicos de biologia e articulem com os conhecimentos pedagógicos, superando com a dicotomia existente nos cursos de formação docente entre esses conhecimentos.

Ainda, é perceptível a importância do jogo no processo de construção de conhecimento acerca do tema Vacina, pois assim como destacado em uma das categorias, possibilitou a aprendizagem do conteúdo de forma prazerosa, estimulando o processo de imaginação e socialização dos participantes, dessa forma, contribui para a superação da Pedagogia Tradicional, presente de forma hegemônica nas escolas brasileiras. Portanto, é necessário que os cursos de formação docente forneçam subsídios teórico-práticos para que os futuros professores justifiquem a incorporação desse tipo de atividade em suas práticas docentes.

\section{REFERÊNCIAS}

ALVES, L.; BIANCHIN, M. A. O jogo como recurso de aprendizagem. Revista Psicopedagogia, v. 27, n. 83, p. 282-287, 2010.

BRASIL. Ministério da Educação. Secretaria de Educação Média e Tecnologia. Parâmetros curriculares nacionais. Brasília: MEC/SEMT, 1999.

CAMPOS, L. M. L.; FELICIO, A. K. C.; BORTOLOTO, T. M. A Produção de Jogos Didáticos para o Ensino de Ciências e Biologia: Uma Proposta para Favorecer a Aprendizagem. Cadernos dos Núcleos de Ensino, São Paulo, p. 35-48, 2003.

CUNHA, M. B. Jogos no ensino de química: considerações teóricas para sua utilização em sala de aula. Química Nova na Escola, São Paulo, [s. L.], v. 34, n. 2, p. 92-98, 2012.

DESSORDI, A. P; SOUZA, D. C; NASCIMENTO JUNIOR, A. F. O Ensino de ecologia comportamental a partir de um jogo de estratégia sobre territorialidade, alimentação e reprodução da onça-pintada (Panthera onca). Fórum Ambiental da Alta Paulista, v. IV, p. 588-602, 2008

FRISON, L. M. B.; SCHWARTZ, S. Motivação e aprendizagem: avanços na prática pedagógica. In: Ciênc. Let. Porto Alegre, n. 32, p. 117-131, 2002. LEFF, H. Epistemologia Ambiental. São Paulo: Cortez, 3. ed., 2001.

GATTI, B. A. Formação de professores no Brasil: características e problemas. Educação e Sociedade, Campinas, v. 31, n. 113, p. 1355-1379, out.-dez. 2010

GOMES, R. R.; FRIEDRICH, M. A. Contribuições dos jogos didáticos na aprendizagem de conteúdos de Ciências e Biologia. Em: Rio de Janeiro, Anais, EREBIO, 1, 2001.

GURIDI, V.; ARRIASSECQ, I. Historia y filosofía de las ciencias en la educación polimodal: propuesta para su incorporación al aula. Ciênc. educ. (Bauru) [online]. 2004, vol.10, n.3 [citado 2019-05-01], pp.307-316. Disponível em: <http://www.scielo.br/scielo.php?script=sci_arttext\&pid=S1516-73132004000300oo1\&lng=pt\&nrm=iso $>$. ISSN 1516-7313. http://dx.doi.org/10.1590/S1516-731320040003000o1.

JANN, P. N.; LEITE, M. F. Jogo do DNA: um instrumento pedagógico para o ensino de ciências e biologia. Ciências \& Cognição, v. 15, n. 1, p. pp. 282-293, 2010.

KISHIMOTO, T. M. Jogo, Brinquedo, Brincadeira e a Educação. São Paulo: Cortez, 1996.

KRASILCHIK, M. Reformas e realidade: o caso do ensino das ciências. São Paulo em perspectiva, v. 14, n. 1, p. 85-93, 2000.

KUHNE, A. P.; SOUZA, D. C.; NASCIMENTO JUNIOR, A. F. Um dado ecológico como recurso para o ensino interdisciplinar em séries iniciais: um relato de experiência. Educere (Umuarama), v. 6, p. 129-143, 2006. 
LEÃO, D. M. M. Paradigmas contemporâneos de educação: Escola tradicional e escola construtivista. Cadernos de Pesquisa, no 107, p. 187-206, julho/1999.

LIBÂNEO, J. C. Democratização da escola pública: a pedagogia crítico-social dos conteúdos. 27. ed. São Paulo: Edições Loyola, 2012. V.1. 16op

LIBÂNEO, J. C. Formação de Professores e Didática para Desenvolvimento Humano. Educação \& Realidade, Porto Alegre, v. 40, n. 2, p. 629-65o, abr./jun. 2015.

LIBÂNEO, J. C. Pedagogia e pedagogos, para que? 9. ed. São Paulo: Cortez, 2007.

LIMA FILHO, F. S.; CUNHA, F. P.; CARVALHO, F. S.; CARDOSO SO, M. F. A importância do uso de recursos didáticos alternativos no ensino de química: uma abordagem sobre novas metodologias. In: Congresso Brasileiro Conhecer Educação, Goiânia. Congresso Brasileiro Conhecer Educação, 2011.

MACAGNAN, D. C.; NASCIMENTO JUNIOR, A. F. Bingo da bicharada: uma estratégia de ensino de ecologia e educação ambiental e divulgação da fauna brasileira. In: XI Encontro Paranaense de Educação Ambiental, 2008, Londrina. Anais do XI Encontro Paranaense de Educação Ambiental, 2008. p. 1-10.

MATTEWS, M. R. História, filosofia e ensino de ciências: a tendência atual de reaproximação. Caderno Catarinense de Ensino de Física, Florianópolis, v. 12, n. 3, p. 164-214, 1995.

MEDEIROS, M. V.; CABRAL, C. L. O. Formação docente: da teoria A prática, em uma abordagem sócio-histórica. Revista E-curriculum, v. 1, n. 2, p. o, 2006.

MOREIRA, A. F.; SILVA, T. T. (Orgs.). Currículo,Cultura e Sociedade. 8. ed. São Paulo: Cortez, 2005.

MORETTI, V. D., et al. O humano no homem: os pressupostos teórico-metodológicos da teoria históricocultural. Psicologia \& Sociedade, 23(3), 477-485.

NOGUEIRA JÚNIOR, D. C. Elaboração de uma sequência didática para a aprendizagem de valor absoluto e da função modular utilizando a organização curricular em rede. 2008. Tese de Doutorado. Dissertação de Mestrado em Ensino de Ciências e Matemática. Belo Horizonte: PUCMG.

OLIVEIRA, M. M. Sequência didática interativa no processo de formação de professores. Petrópolis, RJ: Vozes, 2013.

OLIVEIRA, T. et al. Escola, conhecimento e formação de pessoas: considerações históricas. Políticas Educativas, v. 6, n. 2, 2013.

OLIVEIRA, V. D. R. B. As dificuldades da contextualização pela história da ciência no ensino de biologia: o episódio da dupla hélice do DNA. Dissertação de Mestrado. Programa de Pós-Graduação em Ensino de Ciências e Educação Matemática. Londrina: Universidade Estadual de Londrina, 2009

PAULA, A. A.; REIS NETO, J. A.; NASCIMENTO JUNIOR, A. F. A participação do museu de história natural da universidade federal de lavras na formação inicial de professores de ciências e biologia. In: $24^{\circ}$ Congresso de PósGraduação da UFLA, 2015, Lavras. Anais do 24º Congresso de Pós-Graduação da UFLA, 2015.

PRETTO, N. D. L. A Ciência nos livros didáticos. Campinas: Editora da Unicamp, 1985

RAZERA, C. C.; TEIXEIRA, P. M. M.; CAMPOS, M. C. A; CONTI, S. R.; ARRUDA, M. S. P. Aspectos evolutivos do conceito de vacina nos livros didático no ensino fundamental. Atas II Encontro Nacional de Pesquisas em Educação em Ciências. Valinhos (SP), 1999.

ROSA, A. B. Aula diferenciada e seus efeitos na aprendizagem dos alunos: o que os professores de biologia tem a dizer sobre isso? Monografia (Graduação em Ciências Biológicas) - Faculdade de Ciências Biológicas, Universidade Federal do Rio Grande do Sul, Porto Alegre. 2012. 43 f. 
SILVA, K. C. O.; LEVANDOSKI, A. A. O Jogo como Estratégia no Processo Ensino-Aprendizagem de Matemática na 6a Série ou $7^{\circ}$ Ano, 2008. Disponível em: http://www.diaadiaeducacao.pr.gov.br/portals/pde/arquivos/16658.pdf. Acesso em: or de maio de 2019.

TARDIF, M.; LESSARD, C.; LAHAYE, L. Os professores face ao saber - esboço de uma problemática do saber docente. Teoria \&amp; Educação, Porto Alegre, n. 4, 1991.

UBERTI, L. Intencionalidade educativa. Educação e Realidade, v. 38 p. 1223, 2013.

ZANON, D. A. V.; SILVA, G. M. A.; OLIVEIRA, R. C. Jogo didático Ludo Químico para o ensino de nomenclatura dos compostos orgânicos: projeto, produção, aplicação e avaliação. Ciências \& Cognição, v. 13, n. 1, 2008.

Julia Amorim Monteiro: Graduanda em licenciatura em Ciências Biológicas pela Universidade Federal de Lavras. Membro do Grupo de Estudo em Educação Científica e Ambiental (GEECA) e do Núcleo de Estudo de História e Filosofia da Ciência (NEHFIC). Ex-bolsista do Programa Institucional de Bolsas de Iniciação à Docência (PIBID) subprojeto Biologia e atualmente bolsista do Programa Residência Pedagógica, subprojeto Biologia, Química e Filosofia.

E-mail: juliaamonteirog@gmail.com

Augusto Antonio de Paula: Graduado em licenciatura em Ciências Biológicas pela Universidade Federal de Lavras-MG (2019). Membro do Grupo de Estudo em Educação Científica e Ambiental (GEECA) e do Núcleo de Estudo de História e Filosofia da Ciência (NEHFIC). Ex-bolsista do Programa Institucional de Bolsas de Iniciação à Docência (PIBID) subprojeto Biologia e ex-bolsista do Programa Residência Pedagógica, subprojeto Biologia, Química e Filosofia.

E-mail: augustodiipaula@gmail.com

Antonio Fernandes Nascimento Júnior: Doutor em Educação para a Ciência, Faculdade de Ciências da UNESP campus Bauru-SP e Doutor em Ciências Biológicas (Genética) [Rib. Preto] pela Universidade de São Paulo. Atualmente é professor adjunto da Universidade Federal de Lavras atuando nas disciplinas de Metodologia de Ensino e é Coordenador do subprojeto Biologia, Química e Filosofia do Programa Residência Pedagógica. Tem experiência na área de Biologia Geral e de Ensino, com ênfase em História e Filosofia da Biologia, atuando principalmente nos seguintes temas: educação ambiental, ensino de ciências e biologia, produção de material alternativo, jogos pedagógicos e formação de professores.

E-mail: toni nascimento@yahoo.com.br 